\section{The Influence of Harvest Time on Sensory Properties and Consumer Acceptance of Sweet Cherries}

\author{
Maite A. Chauvin ${ }^{1}$, Matthew Whiting ${ }^{2}$, and Carolyn F. Ross ${ }^{1,3}$
}

AdDitional INDEX WORDs. fruit maturity, quality, Prunus avium

Summary. The objective of this study was to identify the influence of harvest time on sensory attributes of sweet cherries (Prunus avium) as evaluated by a trained and consumer panel. Over three separate panel days, trained and consumer panelists evaluated 'Sweetheart' cherries that were harvested 3 days before commercial maturity (early harvest), at commercial maturity (midharvest), and 3 days postcommercial maturity (late harvest). Fruit attributes from each harvest time were characterized empirically by quantifying soluble solids concentration, exocarp color, and firmness. A sensory panel $(n=12)$, trained to recognize and evaluate the attributes of cherry appearance (color intensity), texture (flesh firmness and juiciness), and flavor/taste (sweetness, sourness, and cherry flavor intensity), evaluated the fruit. Fruit were then evaluated by a consumer panel for purchase intent, overall acceptance, appearance, flavor, and texture. From the trained panel results, late-harvest cherries were higher in color and flavor intensity. Midharvest cherries were highest in firmness, while early-harvest cherries were lowest in color intensity and sweetness. Consumer panel results indicated midharvest and late-harvest cherries had the highest overall acceptance, and midharvest cherries had the highest acceptance for appearance. Overall acceptance was strongly correlated to flavor acceptance $(r=0.94)$. These results indicated that cherries harvested at midharvest were the most preferred of the harvest times despite not having the highest intensities of color, sweetness, or flavor. This indicated the importance of color, sweetness, and flavor of cherries on the overall acceptance and the possible interaction of these attributes in consumer acceptance. Furthermore, the results suggest that standard harvest maturity indicator (i.e., red coloration of exocarp) was appropriate for optimum consumer acceptance of 'Sweetheart'. More broadly, these results suggest that there is some flexibility for the grower with regards to 'Sweetheart' cherry harvest and acceptable sensory properties.

$\mathrm{S}$ weet cherry production has increased worldwide over the past 10 years due to high consumer demand and good returns to growers. This is particularly true in the Pacific northwestern United States where production has doubled in 8 years. Increased production elevates competition among growers for the limited supply of skilled harvest laborers. As a result, growers may begin harvest before the fruit achieves ideal harvest maturity to secure a labor force. Furthermore, it is not unusual for fruit to be harvested past optimum maturity due to an insufficient labor force.

Optimum commercial maturity of sweet cherry fruit is generally determined by red coloration of fruit

\footnotetext{
${ }^{1}$ School of Food Science, Washington State University, Pullman, WA 99164

${ }^{2}$ Department of Horticulture and Landscape Architecture, Irrigated Agriculture Research and Extension Center, Washington State University, Prosser, WA 99350

${ }^{3}$ Corresponding author. E-mail: cfross@wsu.edu.
}

exocarp, with a dark red/mahogany thought of as ideal for the industry standard cultivar, Bing (Kappel et al., 1996). We could find no published reports that assess attributes of new sweet cherry cultivars in relation to eating quality and consumer preference. The development of important quality attributes is not consistent among sweet cherry cultivars $(M$. Whiting, unpublished data) and therefore, a dark red skin color may not be the ideal harvest maturity for new cultivars. In the competitive sweet cherry market, it is desirable to deliver an acceptable product to the con- sumer. Therefore, it is important to understand the impact of harvest time and fruit maturity on fruit quality attributes and the sensory acceptance of the fruit.

Product quality is assessed by various means, but ultimately is judged by the consumer. Consumer assessments of cherry fruit quality are based on the fruit's external and internal characteristics. Visual cues of sweet cherry quality include the presence/absence of defects such as pitting and bruising, fruit shape, size, pedicel color and thickness, and exocarp coloration. Previous research has underscored the importance of exocarp color, with consumers preferring a dark red or mahogany to lighter and darker-colored fruit (Long et al., 2007). Purchase decisions are based upon visual assessment (i.e., perceived quality) and price. Important sweet cherry quality traits include fruit size, fruit color, firmness, and sweetness (Sloulin, 1990). Consumer acceptance of sweet cherries appears to be most related to sweetness, flavor intensity, and skin color (Cliff et al., 1996; Crisosto et al., 2003). For other stone fruit, the most important factors that influence the decision to purchase peaches (Prunus persica), plums (Prunus domestica), and nectarines (P. persica) were: safety of the fruit, healthy, sweet, good appearance, good value, firmness, and ripeness (Wolf et al., 2003).

Cherries have a relatively short fresh market season due to high fruit perishability (Dever et al., 1996). Furthermore, the optimum "harvest window" (i.e., period of time in which fruit are at optimum harvest maturity and storability) is perceived to be very short for sweet cherries. This underscores the importance of harvesting fruit at the ideal time. From a cherry growers' perspective, the examination of the adjustment of harvest date may allow more flexibility with regard to harvest time and

\begin{tabular}{llll}
\hline $\begin{array}{l}\text { Units } \\
\text { To convert U.S. to SI, } \\
\text { multiply by }\end{array}$ & U.S. unit & SI unit & $\begin{array}{l}\text { To convert SI to U.S., } \\
\text { multiply by }\end{array}$ \\
\hline 10 & $\%$ & $\mathrm{~g} \cdot \mathrm{L}^{-1}$ & 0.1 \\
29.5735 & $\mathrm{fl} \mathrm{oz}$ & $\mathrm{mL}$ & 0.0338 \\
2.54 & inch $(\mathrm{es})$ & $\mathrm{cm}$ & 0.3937 \\
0.4536 & $\mathrm{lb}$ & $\mathrm{kg}$ & 2.2046 \\
1.1161 & $\mathrm{Oz} /$ inch & $\mathrm{g} \cdot \mathrm{mm}^{-1}$ & 0.8960 \\
$\left({ }^{\circ} \mathrm{F}-32\right) \div 1.8$ & ${ }^{\circ} \mathrm{F}$ & ${ }^{\circ} \mathrm{C}$ & $\left(1.8 \times{ }^{\circ} \mathrm{C}\right)+32$
\end{tabular}


perhaps an early or late delivery of acceptable cherries to the market for purchase.

Several previous studies have examined the relationship between analytical assessment of cherry quality and sensory evaluation. A trained panel was employed to evaluate sensory properties of cherries and to compare trained panel performance to analytical assessments (Cliff et al., 1996). Results showed a moderate correlation $(r=0.78)$ between perceived sweetness and the soluble solids concentration (SSC) to titratable acidity (TA) ratio (SAR). A high correlation was found between sourness and TA $(r=0.82)$ and sourness and SAR $(r=-0.93)$. However, flavor/texture liking was unrelated to any of the analytical variables. Another study used consumer evaluations and analytical determinations to evaluate sweet cherries, but correlations were not determined between the two evaluations (Crisosto et al., 2003).

The objective of this study was to determine fruit quality differences and consumer preference for 'Sweetheart' sweet cherries harvested at different times: early harvest, midharvest and late harvest. This study used trained sensory panelists to provide a description of the sensory properties of the cherries, and consumer panelists to determine sensory acceptance of the cherries.

\section{Materials and methods}

Cherry sAmples. 'Sweetheart' sweet cherries were harvested in 2008 from an orchard just north of
Prosser, WA (lat. $\left.46^{\circ} 17^{\prime} \mathrm{N}\right)$, on 6,9 , and 14 July. Trees were 5 years old and were grown following standard commercial practices. Row orientation was north-south and trees were trained to a Y-trellised architecture. On each harvest day, $\approx 30 \mathrm{~kg}$ of fruit were picked between 0600 and 0700 HR. Random samples of about 100 to 200 fruit were collected in triplicate for analytical assessment of quality attributes and the remainder was transported to Pullman, WA, for use in panel tests. Fruit were transported under refrigeration at $4{ }^{\circ} \mathrm{C}$. Over $3 \mathrm{~d}$, trained and consumer panelists evaluated 'Sweetheart' cherries that were harvested $3 \mathrm{~d}$ before commercial maturity (early harvest), at commercial maturity (midharvest), and $5 \mathrm{~d}$ postcommercial maturity (late harvest).

Analytical assessment of FRUIT QUALITY. Fruit quality was assessed empirically on three random subsamples of about 100 fruit. Fruit were weighed individually and were then scored visually for skin color on a 1 to 7 scale [Center Technique Interprofessionnel des Légumes (CTIFL), Paris] with 1 being very light red and 7 being very dark mahogany. Fruit firmness was determined using the industry standard equipment (FirmTech 2; Bioworks, Wamego, KS). SSC was determined on juice expressed from five fruit samples using a pocket refractometer (PAL-1; Atago, Bellevue, WA). TA was determined by titrating $10 \mathrm{~mL}$ of juice and $10 \mathrm{~mL}$ of distilled water with $0.1 \mathrm{~N}$ sodium hydroxide $(\mathrm{NaOH})$ to a $\mathrm{pH}$ endpoint of 8.1 and was expressed as milliliters of $\mathrm{NaOH}$ added to reach pH 8.1.

Trained panel. The sensory panel was composed of 12 panelists (five men and seven women), all between the ages of 25 and 69 , with an average age of 41 . Panelists were recruited using advertising from the Washington State University/Pullman community based on their availability and their consumption of fresh cherries at least once per week during local cherry season (e.g., June and July). Panelists were screened for known dental problems and other conditions that may have affected their performance in this panel. A minimum amount of information on the nature of the study was provided to reduce potential bias; panelists were informed that they were assessing the sensory properties of cherries.

The panelists were trained using techniques described by Meilgaard et al. (1999). The cherry attributes were selected using previous literature (Cliff et al., 1996). Panelists received about $10 \mathrm{~h}$ of training during which they learned each attribute definition and evaluation technique. Panelists were trained to recognize the sensory attributes of cherry appearance (color intensity), texture (flesh firmness and juiciness), and flavor/taste (sweetness, sourness, and cherry flavor intensity). Attribute definitions and reference standards are presented in Table 1.

In Session One, panelists completed a demographic questionnaire and were introduced to the $15-\mathrm{cm}$

Table 1. Attribute definitions and standards used by the trained panel for the evaluation of cherries using a 15 - $\mathrm{cm}$ unstructured line scale $(1 \mathrm{~cm}=0.3937$ inch $)$.

\begin{tabular}{|c|c|}
\hline Appearance & Definition \\
\hline Color intensity & $\begin{array}{l}\text { The degree of color intensity from light to dark. A seven-point color comparator [Center Technique } \\
\text { Interprofessionnel des Légumes (CTIFL), Paris] used for anchors at } 0,2.5,5,7.5,10,12.5, \\
\text { and } 15 \mathrm{~cm} \text {, respectively }\end{array}$ \\
\hline \multicolumn{2}{|r|}{$\begin{array}{lll} & \end{array}$} \\
\hline Flesh firmness & $\begin{array}{l}\text { The relative degree of firmness from soft to firm. 'Bing' cherries presorted and classified as soft, intermediate, and } \\
\text { firm were used as anchors at } 1,7.5 \text {, and } 15 \mathrm{~cm} \text {, respectively. }\end{array}$ \\
\hline \multicolumn{2}{|r|}{ 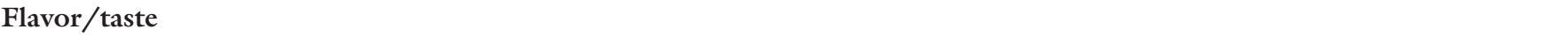 } \\
\hline Sweetness & $\begin{array}{l}\text { The relative degree of sweetness from low to high. Grams of sucrose per liter of water }\left(0,30 \text {, and } 60,1 \mathrm{~g} \cdot \mathrm{L}^{-1}=\right. \\
0.1 \%) \text { used as anchors at } 0,7.5 \text {, and } 15 \mathrm{~cm} \text {, respectively. }\end{array}$ \\
\hline Sourness & $\begin{array}{l}\text { The relative degree of acidity from low to high; Grams of citric acid per liter of water }(0,2 \text {, and } 4) \text { used as } \\
\text { anchors at } 0,7.5 \text {, and } 15 \mathrm{~cm} \text {, respectively. }\end{array}$ \\
\hline
\end{tabular}


scale. In Sessions Two, Three, and Four, panelists were trained to recognize visual attributes, texture, and flavor/taste attributes, respectively. All of the remaining training sessions involved practicing evaluation of the attributes using cherries varying in appearance, flavor/taste, and texture intensities. During these training sessions, a $15-\mathrm{cm}$ line scale was used for each attribute, anchored by the terms "extremely low" $(1 \mathrm{~cm})$ and "extremely high" (14 cm).

Panelist performance was assessed using PanelCheck (version 1.3.1; Danmarks Tekniske Universitet, Copenhagen, Denmark). Panelist validity was assessed through deviation from group mean and reliability was assessed through duplicate evaluations. Panelists were provided with feedback following each training session, with additional training provided if necessary. Three formal practice evaluations were conducted in individual sensory booths equipped with laptop computers to familiarize panelist with the computer program (Compusense ${ }^{\circledR}$ five, release 4.6; Compusense, Guelph, ON, Canada) that was used during data collection.

TRAINED SENSORY PANEL EVALUATIONs. Following analytical evaluations (Prosser, WA), cherry samples were presented to each panelist for evaluation. For each harvest time, panelists were presented with a total of four samples per session (one cherry per sample), with each sample being presented one at a time. Thus, the fruit from each harvest time were evaluated four times on the same day by each panelist. Evaluations took place in individual sensory booths equipped with laptop computers for recording data and under natural light conditions and at room temperature. The cherry samples were identified using a three-digit code. Panelists first evaluated the intensity of the cherry appearance (color intensity). The panelists then tasted the sample and evaluated the texture (flesh firmness and juiciness) and the flavor/taste (sweetness, sourness, and cherry flavor intensity) of each cherry. Panelists were presented with water, saltine crackers, and expectoration cups to cleanse the palate between samples. Results were collected using Compusense ${ }^{\circledR}$ five software.

Data Analysis. The sensory data were subjected to three-way analysis of variance (ANOVA) using panelist, replicate, and cherry as main effects with appropriate interactions. Tukey's honestly significant difference (HSD) was calculated to interpret the differences in attributes between harvest times. Principal component analysis (PCA) was applied to sensory attributes as a function of attribute means for replicate evaluations. SAS (version 9.1; SAS Institute, Cary, NC) and XLSTAT (version 7.5.3; Addinsoft, Paris) were used for all statistical analyses. Significance for all analyses was defined as $P \leq 0.05$.

Consumer panel. The consumer sensory panel was conducted over $3 \mathrm{~d}$, a different day for each harvest time. All panelists were between the ages of 18 and 75 . For the early-harvest cherries, 72 consumers performed evaluations. For midharvest and late-harvest cherries, 100 consumers performed evaluations. Panelists were recruited using advertising in the Washington State University /Pullman community. Panelists were awarded a small nonmonetary incentive for their participation.

Evaluations took place in individual sensory booths equipped with laptop computers for recording data. The cherries were presented at room temperature under natural lighting conditions. Cherry selections were identified using three-digit codes and presented one at a time to panelists. Panelists were presented with two cherries per sample plate, with three flights per session. Thus, each panelist evaluated each cherry harvest time in triplicate. Panelists were first asked to complete a demographics questionnaire, followed by evaluations for overall acceptance and the acceptability of color, texture, and flavor/taste for each cherry harvest time; all evaluations were made using a seven-point scale $(1=$ dislike very much, $7=$ like very much) (Meilgaard et al., 1999). For each sample, panelists were then asked their willingness to pay $\$ 2.99 / \mathrm{lb}$ for cherries using a five-point scale $(1=$ definitely buy, $5=$ definitely not buy). During the evaluation, panelists were instructed to cleanse their palates between samples with saltine crackers and water. Results were collected using Compusense ${ }^{\circledR}$ five software.

Data Analysis. The sensory data were subjected to two-way ANOVA using panelist and cherry as main effects. Tukey's HSD was calculated to interpret the differences in sensory attributes between harvest times using SAS and XLSTAT. Correlation analysis was conducted to identify correlations between attributes. PCA was applied to sensory attributes as a function of replicate mean using XLSTAT. Significance was established at $P \leq 0.05$.

\section{Results and discussion}

Analytical evaluations. Harvest date had an impact on key fruit quality attributes. Fruit skin color was similar for early-harvest and midharvest fruit, but darker red for the lateharvested fruit (Table 2). The 2.7 CTIFL skin color rating of the earlyand midharvest fruit was lighter than the ideal skin color of CTIFL 5 reported by Kappel et al. (1996) from work on unidentified sweet cherry cultivars and selections. Sweet cherry skin color darkens as fruit ripen and consumers use color to determine freshness (Kappel et al., 1996; Proebsting and Mills, 1981); however, there is no relationship between skin color and other key quality attributes when comparing different cultivars

Table 2. Separation of three harvest times of 'Sweetheart' sweet cherries based on soluble solids concentration (SSC), degree of color intensity, and firmness. Mean values of SSC, color, and firmness are presented $(n=10)$.

\begin{tabular}{llcr}
\hline Harvest time $^{\mathrm{z}}$ & SSC (\%) & $\begin{array}{c}\text { Color intensity } \\
(\mathbf{l}-7 \text { scale })^{\mathbf{y}}\end{array}$ & $\begin{array}{c}\text { Firmness } \\
\left(\mathbf{g} \cdot \mathbf{m m}^{-\mathbf{1}}\right)^{\mathbf{x}}\end{array}$ \\
\hline Early harvest & $19.28 \mathrm{a}^{\mathrm{w}}$ & $2.65 \mathrm{a}$ & $303.80 \mathrm{a}$ \\
Midharvest & $19.43 \mathrm{a}$ & $2.73 \mathrm{a}$ & $281.95 \mathrm{~b}$ \\
Late harvest & $19.49 \mathrm{a}$ & $3.51 \mathrm{~b}$ & $264.61 \mathrm{c}$ \\
\hline
\end{tabular}

${ }^{\mathrm{z} E a r l y}$ harvest $=3 \mathrm{~d}$ before commercial harvest, midharvest $=$ commercial harvest, late harvest $=5 \mathrm{~d}$ after commercial harvest.

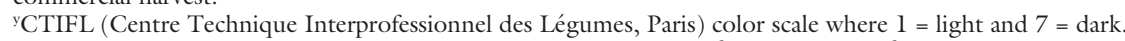
${ }^{x}$ Determined by the FirmTech 2 (Bioworks, Wamego, KS); $1 \mathrm{~g} \cdot \mathrm{mm}^{-1}=9.8100 \mathrm{~N} \cdot \mathrm{m}^{-1}$.

within each analytical measurement (column), a different letter indicates a significant difference via Tukey's honestly significant difference (HSD) test at $P \leq 0.05$ 
(M. Whiting, unpublished data). 'Bing' for example, is a cultivar that has low SSC (e.g., <18\%) at CTIFL skin color rating of 2 to 3 . In contrast, 'Sweetheart' appears to accumulate high SSC at relatively light skin color (i.e., apparently immature). Indeed, SSC was high and not different among the harvest timings (Table 2) despite fruit having different skin color and being harvested up to $8 \mathrm{~d}$ apart. Fruit firmness was different for all harvest times, with early-harvest cherries having the highest firmness and late-harvest cherries being the softest (Table 2). This trend reflected the softening of fruit flesh during ripening and has been reported previously for 'Bing' (Proebsting and Mills, 1981).

Based strictly upon empirical assessment of fruit quality at the different harvest dates, the early-harvest 'Sweetheart' cherries would likely be rated as the best quality. This is due predominantly to their having similar SSC and color, but higher firmness than fruit picked later.

Sensory evaluation. Trained panel assessments of fruit quality provided a useful comparison with instrument-based assessments (Table 3 ). No differences between panelists or replicate sessions were observed based on ANOVA. Differences among the early-harvest, midharvest, and late-harvest cherries were observed for all sensory attributes, including those where instrument-based analyses revealed no differences. Color intensity and sweetness were highest in the late-harvest cherries and lowest in the early-harvest fruit. Cherries harvested at midseason were perceived as the most firm and the early- and lateharvest fruit were similar. Flavor intensity was greater in the late-harvest cherries compared with the other two. No differences in juiciness or sourness were observed between the three harvest times. Sweetness was lowest in the early-harvest cherries.

Color, sweetness, and flavor intensity for late-harvest maturity cherries showed high-intensity means. These results corroborated those from a study by Dever et al. (1996), who compared 'Bing' cherries from a third harvest (characterized as a midseason harvest) to 'Bing' cherries from a fifth harvest (late harvest). In comparing these two harvest times, the authors found that cherry flesh

Table 3. Separation of 'Sweetheart' cherries at early harvest, midharvest, and late harvest based on evaluation of sensory attributes by the trained panel $(n=12)$ using a $15-\mathrm{cm}$ unstructured line scale. Mean values for color intensity, firmness, juiciness, sweetness, sourness, and flavor intensity are presented $(n=48)$.

\begin{tabular}{|c|c|c|c|}
\hline \multirow[b]{3}{*}{ Cherry attribute } & \multicolumn{3}{|c|}{ Harvest time ${ }^{\mathrm{z}}$} \\
\hline & Early harvest & Midharvest & Late harvest \\
\hline & \multicolumn{3}{|c|}{ Mean value $(\mathrm{cm})^{\mathrm{y}}$} \\
\hline Color intensity & $6.04 \mathrm{a}^{\mathrm{x}}$ & $7.55 \mathrm{~b}$ & $8.69 \mathrm{c}$ \\
\hline Firmness & $7.00 \mathrm{a}$ & $8.50 \mathrm{~b}$ & $7.35 \mathrm{a}$ \\
\hline Juiciness & $10.79 \mathrm{a}$ & $10.62 \mathrm{a}$ & $10.52 \mathrm{a}$ \\
\hline Sweetness & $8.07 \mathrm{a}$ & $9.31 \mathrm{~b}$ & $10.00 \mathrm{~b}$ \\
\hline Sourness & $9.04 \mathrm{a}$ & $8.56 \mathrm{a}$ & $8.31 \mathrm{a}$ \\
\hline Flavor intensity & $8.90 \mathrm{a}$ & $9.41 \mathrm{a}$ & $10.49 \mathrm{~b}$ \\
\hline
\end{tabular}

${ }^{\mathrm{z}}$ Early harvest $=3 \mathrm{~d}$ before commercial harvest, midharvest $=$ commercial harvest, late harvest $=5 \mathrm{~d}$ after commercial harvest.

yTrained panel scores were evaluated along a $15-\mathrm{cm}$ unstructured line scale anchored by the terms "extremely high" $(14 \mathrm{~cm})$ and "extremely low" $(1 \mathrm{~cm}) ; 1 \mathrm{~cm}=0.3937$ inch.

${ }^{x}$ Within each harvest time (column), a different letter indicates a significant difference via Tukey's honestly significant difference (HSD) test at $P \leq 0.05$.

firmness decreased, juiciness and sourness did not change, and sweetness and cherry flavor increased. This study also reported that a first harvest of 'Bing' cherries was higher in sourness compared with a second 'Bing' harvest.

Instrumental assessments of fruit SSC showed no differences between the three harvest times (Table 2). In contrast, trained panelists perceived an increase in sweetness with each harvest date, with the mid- and lateharvested fruit being rated sweeter than early-harvested fruit $(P \leq 0.05)$. These trained panel results are supported by the sugar-to-acid ratios of the cherries. The early-harvest cherry was found to have the lowest sugarto-acid ratio (13:1), while the lateharvest cherry had the highest ratio (16:1). Cliff et al. (1996) reported a weak correlation between SSC and perceived sweetness. In the present study, together with this increase in sweetness, cherry color intensity also increased. Crisosto et al. (2003) found that as cherry skin color turned from light to dark, there was a corresponding increase in SSC. The present study found similar results with the trained panel evaluations.

The position of the sensory attributes of 'Sweetheart' cherries on the PCA plot as evaluated by the trained sensory panel is presented in Fig. 1. PCl described $58.2 \%$ of the variation and was primarily described by flavor and color intensity. PC2 described $22.2 \%$ of the variation and was primarily defined by and juiciness firmness. A clear separation among harvest timings was observed. Early- harvest cherries were defined by highintensity ratings for sourness and low ratings for sweetness, flavor intensity, firmness, and juiciness. Cherries picked at midharvest were described by their high intensity of flavor and color intensity or high juiciness, while late-harvest cherries had high intensities of sweetness, color, and flavor.

Following the analytical and trained panel evaluation of the cherries, a consumer panel was used as the third approach to evaluate the quality of the cherries. Overall acceptance was higher in the midharvest and late-harvest cherries compared with the early-harvest cherries (Table 4). Consumers had greater acceptance of the midharvest cherries compared with the early or late-harvest cherries. In terms of texture, the midharvest cherries were higher in acceptance compared with the late-harvest cherries, with the early-harvest cherries in between. Consumers rated their acceptance of flavor of early-harvest cherries lower than the other two harvest times, which were similar. Overall, these results indicated that for all attributes, including overall acceptance, cherries harvested at midseason maturity were the most accepted of the three harvest times. However, this apparent preference for midharvest fruit was not reflected in the consumers' willingness to pay $\$ 2.99 / \mathrm{lb}$ cherries. No differences were found between the three harvest times. These results indicate that on the whole, consumers accepted all cherries, with the lowest score for any attribute being 5.5 on a sevenpoint scale. 


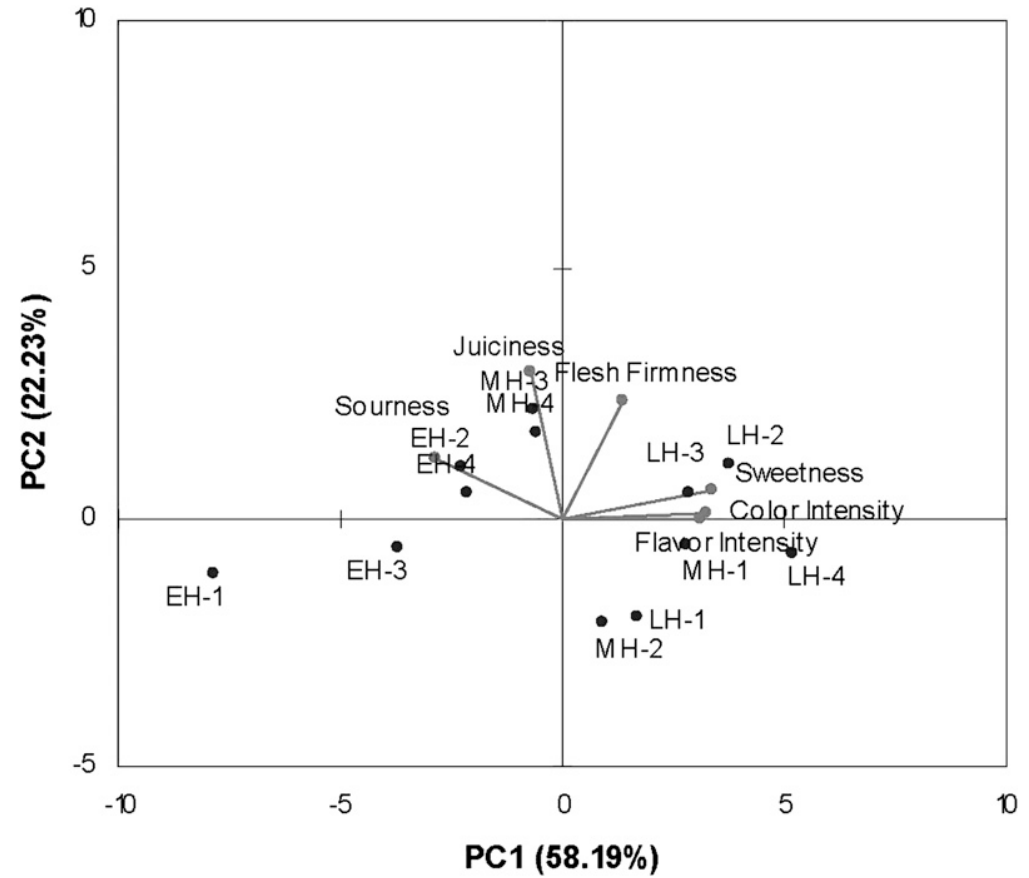

Fig. 1. Position of the sensory attributes of early harvest $(\mathrm{EH})$, midharvest $(\mathrm{MH})$, and late harvest $(\mathrm{LH})$ 'Sweetheart' cherries on the principal components analysis (PCA) plot as evaluated by the trained sensory panel. Separation was along principal component 1 [ PCl (58.19\%)] and PC2 (22.23\%)]. EH-1, EH-2, EH-3, and EH-4 represent the mean of 12 evaluations for four replicate cherry samples harvested $3 \mathrm{~d}$ before commercial harvest. $\mathrm{MH}-1, \mathrm{MH}-2, \mathrm{MH}-3$, and $\mathrm{MH}-4$ represent the mean of 12 evaluations for four replicate cherry samples at commercial harvest. LH-1, LH-2, $\mathrm{LH}-3$, and LH-4 represent the mean of 12 evaluations for four replicate cherry samples harvested $\mathbf{5} \mathrm{d}$ after commercial harvest.

Table 4. Separation of 'Sweetheart' cherries at different harvest times based on overall acceptance and acceptance of appearance, texture, and flavor/taste attributes as evaluated by the consumer panel $(n=72$ for early harvest, $n=100$ for mid- and late harvest). Mean values for attribute intensity are presented ( $n=216$ for early harvest and $\mathbf{n}=\mathbf{3 0 0}$ for mid and late harvest).

\begin{tabular}{|c|c|c|c|}
\hline \multirow[b]{3}{*}{ Cherry attribute } & \multicolumn{3}{|c|}{ Harvest time ${ }^{\mathrm{z}}$} \\
\hline & Early harvest & Midharvest & Late harvest \\
\hline & \multicolumn{3}{|c|}{ Hedonic scores $(1-7 \text { scale })^{\mathrm{y}}$} \\
\hline Overall acceptance & $5.71 \mathrm{a}^{\mathrm{x}}$ & $5.98 \mathrm{~b}$ & $5.90 \mathrm{ab}$ \\
\hline Appearance & $6.14 \mathrm{a}$ & $6.32 \mathrm{~b}$ & $6.14 \mathrm{a}$ \\
\hline Texture & $6.06 \mathrm{ab}$ & $6.18 \mathrm{~b}$ & $5.91 \mathrm{a}$ \\
\hline Flavor/taste & $5.49 \mathrm{a}$ & $5.75 \mathrm{~b}$ & $5.77 \mathrm{~b}$ \\
\hline
\end{tabular}

${ }^{\mathrm{z}}$ Early harvest $=3 \mathrm{~d}$ before commercial harvest, midharvest $=$ commercial harvest, late harvest $=5 \mathrm{~d}$ after commercial harvest.

${ }^{y}$ Hedonic scores ranged from 1 to 7 where $1=$ dislike very much and $7=$ like very much.

${ }^{x}$ Within each harvest time (column), a different letter indicates a significant difference via Tukey's honestly significant difference (HSD) test at $P \leq 0.05$.

Separation of the cherries by consumers harvested at the three harvest times is shown in Fig. 2. PCl described $73.4 \%$ of variation and had heavy positive loadings for appearance and overall acceptance. PC2 described $21.5 \%$ of the variation in the data with a positive loading for texture. Clear separation between the cherries from the three harvest dates was observed. Early-harvest cherries were characterized by lower overall and flavor acceptance. Cherries harvested at midseason were generally rated positively for all attributes. Late-harvest cherries were characterized by lower acceptance of texture and appearance compared with the other two timings.

Pearson correlations among cherry harvest times indicated that one of the main drivers of overall acceptance of cherries by consumers was flavor/taste $(\mathrm{r}=0.94)$ (Table 5$)$. For the consumer evaluations, sweetness, sourness, and flavor intensity were not evaluated separately as they were for the trained panel. Therefore, the definition of "flavor" as evaluated by the consumer panel included many attributes. A previous study also reported a strong correlation between liking and flavor, with a slightly weaker correlation between liking and sweetness (Dever et al., 1996). Flavor and sweetness intensities have been reported to be the best predictors of flavor/texture liking of cherries (Cliff et al., 1996). Cliff et al. (1996) also showed cherry flavor intensity to be highly correlated with the sum of sweetness and sourness. Another study found that high consumer acceptance of 'Brooks' and 'Bing' cherries was highly dependent upon SSC, with results indicating that SSC needed to be at least $16 \%$ to satisfy the majority of American consumers (Crisosto et al., 2003). Another study (Kappel et al., 1996) found a linear relationship between SSC and favorable cherry rating, suggesting a minimum SSC for optimal acceptance of sweet cherries to be $15 \%$. As SSC increased as fruit matured, the highest SSC or sweetness value was expected in the lateharvest fruit as was observed in the trained panel results (Table 3 ). Even though the late-harvest fruit was the sweetest, it did not have the highest overall acceptance, indicating the importance of other attributes, such as sourness, flavor, and texture on sweet cherry acceptance.

Appearance had a positive correlation with overall acceptance $(\mathrm{r}=$ 0.73 ) in this study. These findings agreed with a study conducted by Crisosto et al. (2003), who reported a strong influence of appearance on cherry purchase, with the highest percentage $(64 \%-80 \%)$ of consumers deciding to purchase 'Bing' and 'Brooks' cherries based upon their dark skin color. Another study (Cliff et al., 1996) also found that color had an impact on consumer acceptance of cherries, with consumers preferring a uniform, darker cherry. In the present study, the consumers evaluated overall appearance and not specifically color. Thus, "appearance," as evaluated by the consumers, may have included other parameters such as 


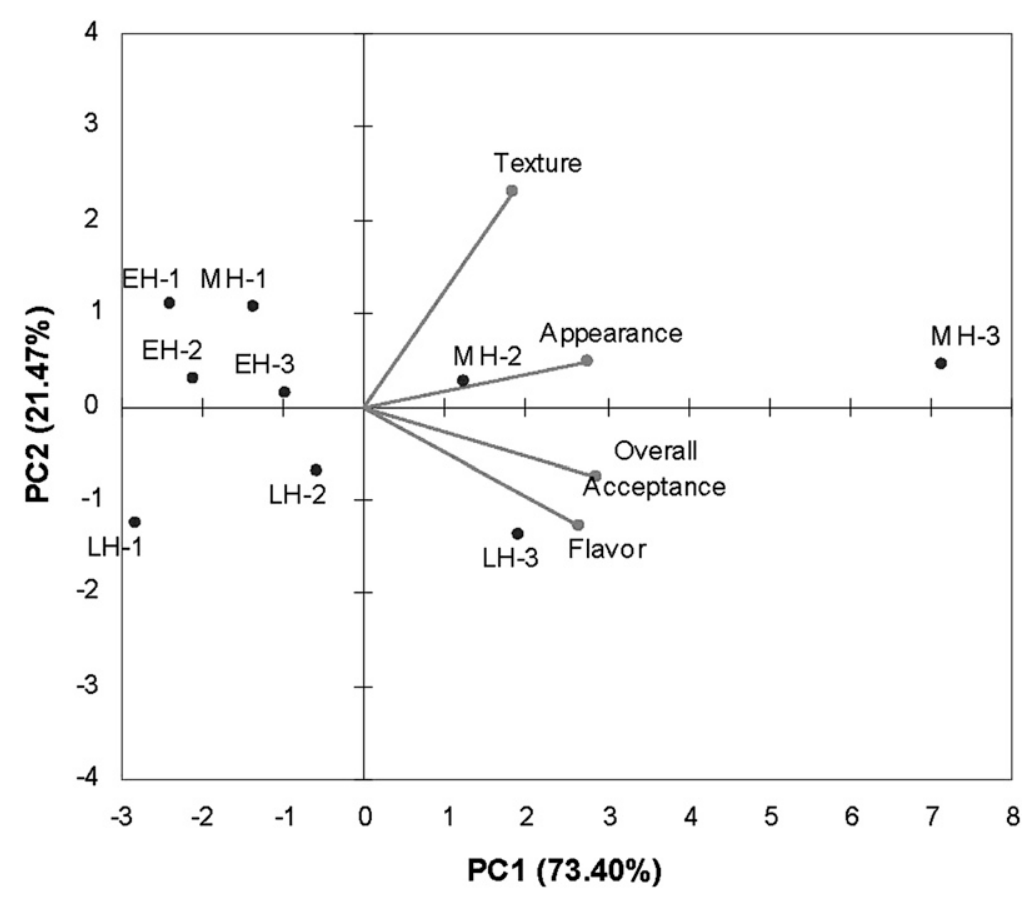

Fig. 2. Position of the sensory attributes of early $(\mathrm{EH})$, midharvest $(\mathrm{MH})$, and late harvest $(\mathrm{LH})$ 'Sweetheart' cherries on the principal components analysis (PCA) plot as evaluated by the consumer sensory panel. Separation was along principal component [ PCl (73.40\%)] and PC2 (21.47\%)]. EH-1, EH-2, and EH-3 represent the mean of 72 evaluations for three replicate cherry samples harvested $3 \mathrm{~d}$ before commercial harvest. $\mathrm{MH}-1, \mathrm{MH}-2$, and $\mathrm{MH}-3$ represent the mean of 100 evaluations for three replicate cherry samples at commercial harvest. LH-1, LH-2, and $\mathrm{LH}-3$ represent the mean of 100 evaluations for three replicate cherry samples harvested $5 \mathrm{~d}$ after commercial harvest. $\mathrm{PC}=$ principal component.

Table 5. Pearson correlations between overall acceptance and acceptance of appearance, texture, and flavor/taste of 'Sweetheart' cherries harvested at three harvest times as evaluated by the consumer panel $(n=272)$. No linear relationship is indicated by 0 . A perfect positive linear relationship is indicated by +1 . This means that following an exact linear rule, as one variable increases in its value, the other variable also increases in its value. A perfect negative linear relationship is indicated by -1 : as one variable increases in its value, the other variable decreases via an exact linear rule.

\begin{tabular}{lcccr}
\hline Attributes & Overall acceptance & Appearance & Texture & Flavor \\
\hline Overall acceptance & 1.00 & 0.73 & 0.23 & 0.94 \\
Appearance & 0.73 & 1.00 & 0.83 & 0.44 \\
Texture & 0.23 & 0.83 & 1.00 & -0.13 \\
Flavor/taste & 0.94 & 0.44 & -0.13 & 1.00 \\
\hline
\end{tabular}

speckles and stem length, which were not as useful as color uniformity and size on predicting visual liking (Cliff et al., 1996).

Texture showed the weakest correlation to overall acceptance $(\mathrm{r}=$ $0.227)$. In a study of the attributes of an ideal sweet cherry, panelists indicated there was an ideal firmness value associated with a cherry (Kappel et al., 1996). In the present study, the analytical evaluations indicated a clear separation of cherries based on firmness; however, this separation was not observed with the trained panel (Table 3) or the consumer panel (Table 4). These results reflected a lack of panelist sensitivity to changes in texture or a large range in texture liking.

Table 6 shows the frequency of consumer comments about the cherries at the different harvest times. Comments about the sweetness and sourness of the cherries had the highest frequency, indicating the importance of these attributes to the consumers. These results support the early results from Table 5 showing the correlation between overall acceptance and flavor. Cherry texture provoked fewer comments, suggesting that these properties were not as important to the consumers when making comments about the cherries. No comments about appearance were noted. The frequency of comments about the "good firmness" of the midharvest cherries supported the results from Table 4 showing the higher acceptance of midharvest cherries and the lower acceptance of late-harvest cherries.

In this study, three techniques were employed to evaluate cherry quality: analytical evaluations, trained panel, and consumer panel evaluations. The analytical evaluations showed no differences in SSC between the three harvest times, while the trained sensory panel did find differences in sweetness. The consumer panel did not explicitly evaluate "sweetness" acceptance, but flavor/taste acceptance did show the same trends as observed in the trained panel results. Based on a previous study (Cliff et al., 1996), an increase in SSC would increase cherry acceptance. These results indicated that the analytical evaluation was not as sensitive as the sensory evaluations of sweetness or that other factors such as the concentration, temperature, chemical composition of panelist saliva, the presence of other tastants, or the incidence of ageusia may have influenced the panelists' evaluation of sweetness (Meilgaard et al., 1999).

Analytical color evaluation showed the late-harvest cherries to have the darkest color, with earlyharvest and midharvest cherries as lighter. Similar results were observed with the trained panel. Firmness was different when evaluated analytically, with the late-harvest cherries being the least firm and the early-harvest cherries being the most firm. The trained panel results did not show the same clear separation. Identification of subtle textural changes in foods has been shown to be difficult for panelists, as these textural changes are often accompanied by differences or changes in other sensory properties (Corradini et al., 2001).

In summary, for determination of taste/flavor and color quality, sensory evaluation techniques appeared to be the most appropriate, while for 
Table 6. Frequency analysis of consumer comments regarding 'Sweetheart' cherries harvested at early harvest, midharvest, and late harvest by 272 consumers.

\begin{tabular}{|c|c|c|c|c|c|}
\hline \multirow[b]{2}{*}{ Attribute } & \multirow[b]{2}{*}{ Comment } & \multicolumn{3}{|c|}{ Harvest time ${ }^{\mathrm{z}}$} & \multirow[b]{2}{*}{ Total } \\
\hline & & Early harvest & Midharvest & Late harvest & \\
\hline \multicolumn{2}{|c|}{ Taste/flavor attributes } & \multicolumn{4}{|c|}{ Consumer comments (no.) } \\
\hline Sour & “Too sour" & 57 & 58 & 48 & 163 \\
\hline Sweet & "Acceptable sweetness" & 16 & 18 & 16 & 50 \\
\hline Bitter & "Too bitter" & 1 & 1 & 0 & 2 \\
\hline \multicolumn{2}{|c|}{ Texture attributes } & \multicolumn{4}{|c|}{ Consumer comments (no.) } \\
\hline Juicy & "Good juiciness" & 8 & 1 & 2 & 11 \\
\hline Firm & "Good firmness" & 6 & 16 & 6 & 28 \\
\hline Soft & “Too soft" & 7 & 14 & 19 & 40 \\
\hline
\end{tabular}

${ }^{\mathrm{z}}$ Early harvest $=3 \mathrm{~d}$ before commercial harvest, midharvest $=$ commercial harvest, late harvest $=5 \mathrm{~d}$ after commercial harvest.

firmness evaluation, analytical determinations provided good separation.

\section{Conclusions}

Results from this study show the influence of harvest time on the sensory properties and consumer acceptance of sweet cherries. The trained panel profile of the cherries found the midharvest cherries higher in firmness, the late-harvest cherries were highest in color and flavor intensity, and the early-harvest cherries were lowest in sweetness $(P \leq 0.05)$. Consumer panel results indicated midharvest cherries (harvested at commercial maturity) had the highest overall acceptance, and highest acceptance for appearance. Late-harvest cherries had the lowest acceptance for texture, while early-harvest cherries had the lowest acceptance for flavor/taste $(P \leq 0.05)$. Overall acceptance was strongly correlated to flavor acceptance $(r=0.82)$. For cherry quality determinations, the most effective technique depended upon the attribute of interest. Sensory evaluation techniques were the most effective for taste/flavor and color attributes, while analytical measurements were the most effective for firmness determinations.

In a broader sense, these results suggest that cherries harvested at commercial maturity, while not having the highest intensities of color, sweetness, or flavor, were still the most accepted of the harvest times compared. This indicates the importance of a number of sensory attributes of cherries on the overall acceptance and the possible interaction of these attributes in consumer acceptance. In addition, the results indicate that while sensory differences between the cherries harvested at the three times are apparent, the cherries are still accepted by the consumers. This suggests that for 'Sweetheart' cherries, growers do have flexibility in regards to harvest date.

\section{Literature cited}

Cliff, M.A., M.C. Dever, J.W. Hall, and B. Girard. 1996. Development and evaluation of multiple regression models for prediction of sweet cherry liking. Food Res. Int. 28:583-589.

Corradini, M.G., R. Engel, and M. Peleg. 2001. Sensory thresholds of consistency of semiliquid foods: Evaluation by squeezing flow viscometry. J. Texture Stud. 32:143-154.

Crisosto, C.H., G.M. Crisosto, and P. Metheney. 2003. Consumer acceptance of 'Brooks' and 'Bing' cherries is mainly dependent on fruit SSC and visual skin color. Postharvest Biol. Technol. 28: 159-167.

Dever, M.C., R.A. MacDonald, M.A. Cliff, and W.D. Lane. 1996. Sensory evaluation of sweet cherry cultivars. HortScience 31:150-153.

Kappel, F., B. Fisher-Fleming, and E. Hogue. 1996. Fruit characteristics and sensory attributes of an ideal sweet cherry. HortScience 31:443-446.

Long, L.E., M.D. Whiting, and A.B. Marin. 2007. Consumers show preference for key cherry attributes. Good Fruit Grower 58:15-17.

Meilgaard, M., G.V. Civille, and B.T. Carr. 1999. Descriptive analysis techniques, p. 161-172. In: M. Meilgaard, G.V. Civille, and B.T. Carr (eds.). Sensory evaluation techniques. 3rd ed. CRC Press, New York.

Proebsting, E.L. and H.H. Mills. 1981. Effects of season and crop load on maturity characteristics of 'Bing' cherry. J. Amer. Soc. Hort. Sci. 106:144-146.

Sloulin, W. 1990. Cherry quality survey: Status report. Proc. Washington State Hort. Assn. 86:226-227.

Wolf, M.M., A.J. Martin, and T. Cagianut. 2003. An analysis of the importance of ripeness to consumers in the United States when making a purchase decision for peaches, plums, and nectarines. Acta Hort. 604:61-67. 